An exploratory study of corporate singing and organizational culture

By: Bruno Dyck and Arran Caza

Dyck, B., \& Caza, A. (2021). An exploratory study of corporate singing and organizational culture. Journal of Management, Spirituality \& Religion, 18(2), 74-99.

https://doi.org/10.51327/MDON6306

***(C) International Association of Management, Spirituality \& Religion. Reprinted with permission. No further reproduction is authorized without written permission from the International Association of Management, Spirituality \& Religion. This version of the document is not the version of record. $* * *$

\begin{abstract}
:
This study examined corporate singing, specifically when members sing together in religious organizations. Consistent with the literature, we found that organizations whose members participate in corporate singing, versus merely listening to others sing, had more prosocial behavior (i. e., greater voluntarism). In addition, the study examined whether four different types of singing (chanting, unison, harmony, or a combination of types) aligned in predictable ways with the four organizational cultures associated with the Competing Values Framework (bureaucracy, market, clan, and adhocracy, respectively), and found some support for three of the hypothesized relationships. Implications are discussed.
\end{abstract}

Keywords: corporate singing | prosociality | organizational culture | faith-based organizing | Competing Values Framework | music | harmony | unison | melody | well-being

Article:

$* * *$ Note: Full text of article below 


\title{
An exploratory study of corporate singing and organizational culture*
}

\author{
Bruno Dyck \\ Full Professor \\ I.H. Asper School of Business \\ University of Manitoba \\ Winnipeg, Manitoba \\ Canada R3T 5V4 \\ Email: Bruno.Dyck@umanitoba.ca
}

\author{
Arran Caza \\ Associate Professor \\ Department of Management \\ Bryan School of Business and Economics \\ University of North Carolina Greensboro \\ Email: ajcaza@uncg.edu
}

AUTHORS' SUBMISSION COPY OF Dyck, B., \& Caza, A. (2021). An exploratory study of corporate singing and organizational culture. Journal of Management, Spirituality \& Religion, 18(2), 74-99.

Conflict of interest: None to report

*An earlier version of this paper was presented at the 2020 Academy of Management meetings. This paper has benefitted from comments and encouragement from reviewers, Jonathan Dueck, and Kathryn Pavlovich. 


\title{
An exploratory study of corporate singing and organizational culture
}

\begin{abstract}
This study examined corporate singing, specifically when members sing together in religious organizations. Consistent with the literature, we found that organizations whose members participate in corporate singing, versus merely listening to others sing, had more prosocial behavior (i.e., greater voluntarism). In addition, the study examined whether four different types of singing (chanting, unison, harmony, or a combination of types) aligned in predictable ways with the four organizational cultures associated with the Competing Values Framework (bureaucracy, market, clan, and adhocracy, respectively), and found some support for three of the hypothesized relationships. Implications are discussed.
\end{abstract}

Keywords: Corporate singing, prosociality, organizational culture, faith-based organizing, Competing Values Framework, music, harmony, unison, melody, well-being 
Humankind has a long history of singing together, so much so that cultural anthropologists have puzzled over why this practice is so widespread and so persistent (e.g., Fischer et al. 2013). People sing for fun and entertainment, for religious reasons, and when they work. With regard to singing at work, the practice was common in preindustrial times, but was stifled with industrialization, perhaps because it challenged the ability of machines to set the work pace and/or because singing had no apparent utility (e.g., the energy used for singing should be used for productive behavior; Landay and Harms 2019; Prichard, Korczynski and Elmes 2007).

Nonetheless, corporate singing enjoyed a resurgence in the early 1900s, when workplace choirs became common in the USA (Carter 1954). For example, organizations like IBM and Maytag published books of songs about their company that were written and sung by employees at meetings (El-Sawad and Korczynski 2007; Nissley, Taylor and Butler 2003). During this time Japanese firms also became known for their company songs; plant workers and office employees would begin their day with their company's song, do physical exercises to the accompaniment of the company song during the middle of the day, and finish the day with the company song (Suzuki 1985).

Although corporate singing declined again in the latter half of the century (Prichard, Korczynski and Elmes 2007), it seems to be on the rise again since the beginning of the new millennium (e.g., Couture 2018; Giaver, Vaag and Wennes 2017). The best-known contemporary example may be Walmart employees who start their day with a company chant (e.g., Kluver, Frazier and Haidt 2014), but Cook (2017) notes that many well-known American businesses today have workplace choirs (e.g., Google, Facebook, Boeing, LinkedIn), especially firms that appear on "Best Places to Work" lists. Similarly, there has been resurgent interest in company songs in Japan (Hacker and Tsutsui 2006), workplace choirs are on the increase in Ireland (which 
has a Workplace Choir of the Year competition; Moss and O'Donoghue 2018), and the UK has even had a TV series called Sing while you work and an MIO Office Choir of the Year competitions (Blasnes and Jansson 2015; Werber 2019).

Anthropologists and evolutionary psychologists alike have suggested that singing together creates social bonds between people (e.g., Dunbar et al. 2012; Giaver, Vaag and Wennes 2017), which may help to explain the prevalence of national and corporate anthems (e.g., Kapral, 2018; Kingsley, 2011), the frequency of singing together among peace activists (e.g., Brooks 2010; Li 2019; Lynch 2009), and the well-publicized interest in neighborhood singing as a sign of support and solidarity during the COVID-19 crisis (Langley and Coutts, 2020). Proponents of workplace choirs point to their potential to improve many aspects of work: employee engagement, interpersonal relationships, teamwork, employee retention and recruitment, intra-organizational networking, the ability to overcome hierarchical barriers, innovative learning, reduced employee stress, and enhanced employee well-being (e.g., Cook 2017; Werber 2019).

While considerable research has looked at individual benefits from corporate singing (e.g., Giaver et al. 2017), little empirical research has looked at the effects of singing at the organizational level (Giæver 2019, 99), nor specifically at the relationship between organizational culture and the type of singing done in organizations. This paper begins to address this gap by using a sample of religious organizations to explore two research questions. First, the study examines whether singing together increases prosocial values and behaviors in organizations. Second, the study examines whether different types of organizational culture are associated with different types of singing. This association is consistent with the idea that music resides "at the center of culture" (Jackson, 2017, 24). In particular, we examine whether four different types of singing (chanting, unison, harmony, or a combination of types) align with the 
four organizational culture types associated with the Competing Values Framework

(bureaucracy, market, clan, and adhocracy, respectively; Quinn and Rohrbaugh 1983). Our study provides a foundation for the future study of corporate singing, and may help practitioners to use corporate singing in a strategic manner.

The paper is divided into three parts. In the first part, we review relevant literatures to develop six hypotheses. The second part of the paper describes the methods and results from our sample of 73 religious organizations. The final part discusses the implications of our findings.

\section{Literature review}

In most cultures for most of human history, there was an expectation that individuals would "participate actively and collectively in the production and perhaps creation of music," not just in their private lives, but also in their roles as organizational members (Cross, 2006, 116; cited in Begbie, 2017, 15). This expectation no longer holds in Western culture; the more common expectation today is that most individuals will simply listen to music. For example, the little research that there is on music in organizations tends to focus on the effect of listening to music (e.g., listening to happy music increases cooperation; Kniffin et al. 2017). However, as we describe below, there is reason to believe that important organizational effects will stem from having members participate in making music.

\section{Corporate singing and prosocial behavior}

The idea that singing together may contribute to prosocial behaviors is well accepted (e.g., Alvin 1975; Giæver 2019; Luhrs 2015; Prichard et al. 2007). For example, Fischer et al. (2013) showed that music-based rituals can have a positive effect on prosocial behavior. In particular, they argue that synchrony in rituals increases participants' perception of one-ness with others, which in turns increases their commitment to sacred/non-monetary values and intensifies their 
prosocial behaviors. Moreover, members of groups that experienced music-based synchrony (e.g., Buddhist chanting, a form of Hindu devotional singing called Kirtan, a choir, a Brazilian drumming group) displayed more prosocial behavior than members of groups engaged in nonmusical synchrony (e.g., a cross-county running group, a group that played social poker). Along the same lines, a study by Good and Russo (2016) found that in diverse groups of children, group singing resulted in greater prosocial behavior than did group art or competitive games.

Consistent with studies like these, organizational scholars Kluver et al. (2014) draw on Emile Durkheim $(1992,1915)$ to describe how music may help to enhance prosocial behavior. Durkheim's idea of Homo duplex suggests that humans vacillate between having an individual (selfish) level of consciousness versus a collective (groupish) level of consciousness, which in turn influences their social behavior. Whereas Durkheim saw evidence of the shift from individual to collective consciousness when aboriginal people painted their bodies and danced around a campfire, Kluver et al. (2014) see the same when Walmart employees start the day with a chant. Such activities foster a collective consciousness. They may also create a sense of having important external competition and a common fate, thereby facilitating a shift from an individual to a collective consciousness (Kluver et al. 2014). Kluver et al. (2014) argue that entering into a collective consciousness profoundly influences behavior not only when in that state, but long afterward (see also Kagan and Kirchberg 2016; Turino 2008).

There are differing views as to whether the prosocial behaviors associated with group singing extend beyond in-group members. On the one hand, it has been argued that group singing increases prosocial behavior within the group, but that it may also facilitate aggression toward non-group members (Kluver et al. 2014). On the other hand, some argue that corporate singing may be a key contributor to enhancing prosocial behavior universally, a view most 
evident in group singing among social activists in the peace movement (e.g., Brooks 2010;

Eyerman and Jamison 1998; De Avila 2015). Begbie (2017) draws particular attention to the idea that singing in harmony requires there to be a joining of different pitches and voices, making differences among people a strength to be celebrated rather than something that leads to conflict. As a result, there is reason to believe that corporate singing enhances prosocial behavior within, and sometimes beyond, an organization's boundaries.

It is important to note that while any exposure to music can increase prosociality (Kniffen et al. 2017), the effects are greater when individuals participate in the act of singing together, rather than simply listening to music or even singing independently (e.g., Busch and Glick 2012; Luhrs 2015; Turino 2008). For example, an experiment by Anshel and Kipper (1988) found that singing in a group created more trust among members than listening to music in a group, but that both of these conditions created more trust than non-musical group activities (i.e., reading poetry in a group, watching a film in a group). Another experiment by Wiltermuth and Heath (2009) found more prosocial behavior among participants who sang together while performing a task than for participants in a control group with no singing and participants in a group with random singing. They also found that there was no additional improvement in prosocial behavior when physically moving together was added to singing together. In sum, the literature suggests that corporate singing will lead to greater prosocial behavior than corporate listening to music.

Hypothesis 1: Organizations that practice corporate singing have more pro-social values and behavior than organizations that practice only corporate listening.

\section{Organizational culture and corporate singing}

Since music-making has been an integral part of most cultures in history (e.g., Cross 2006), we would expect there to be consistent relationships between corporate singing and 
organizational culture (Jackson 2017). Organizational culture consists of the shared values and norms that influence how organizational members perceive and interact with one another and with their environment (Schein 1985). It can be thought of as "the set of values and assumptions that underlie the statement, "This is how we do things around here'" (Quinn and Rohrbaugh, 1983, 66).

Organizational culture has often been described as having two key dimensions, related to how much an organization values stability versus change, and whether it has an internal versus and external focus (e.g., Quinn and Rohrbaugh 1983). These two dimensions are evident in Schein's (1985) definition of organizational culture as focusing on both internal integration and external adaptation. Internal integration focuses on developing norms and rules within the organization that facilitate stable relations among members, including the distribution of authority within the organization, and sanctions for disobeying rules. External adaptation turns the organization's gaze outward, seeking to ensure that it is attuned to what is happening among key stakeholders (e.g., customers, suppliers, regulators) and to remain flexible and make appropriate changes when needed. Below, we consider how corporate singing is related to both of these dimensions.

First, with regards to internal integration, implicit in the discussion leading to Hypothesis 1 about prosocial behavior is an understanding that corporate singing can connect members of a group to one another (e.g., Moss and O'Donoghue 2018). For example, reciting a sports chant together makes members feel connected to one another (Ehrenreich 2006), singing in one voice on the picket line or during a national anthem brings a sense of solidarity (e.g., Denisoff 1966), and attuning to other harmonious voices in a workplace choir draws members together (Moss and O'Donoghue 2018). These types of singing are all acts of synchrony (e.g., coordinated 
simultaneous behaviors) that participants willingly engage in with a larger corporate body. This intentional synchrony facilitates internal integration, and has an internal stability-oriented focus.

At the same time, corporate singing may also lead to extra-organizational prosocial behavior, and thus corporate singing may facilitate external adaptation (in so far as members seek to be attuned to and address needs of external stakeholders). The crux of the matter is whether corporate singing prompts members to become connected only to other singers within their group, or whether corporate singing makes them feel connected to something beyond their group. With regard to the latter, the literature sometimes describes how music making is an experience in which participants perceive themselves as becoming part of a larger whole, an experience that may connect them to an external force that transcends themselves or their organization (Fischer et al. 2013; Kluver et al. 2017). In this way corporate singing has the potential to contribute to external adaptation.

However, this conclusion is debated. While considerable evidence suggests that corporate singing facilitates internal integration, there is less consensus about its effect on external adaptation. Indeed, there are three main themes in the literature regarding the potential effect of corporate singing vis a vis extra-organizational stakeholders. We explore these three themes more fully in the next section, but they can be summarized as follows. The first theme is that corporate singing may actually facilitate aggression toward extra-organizational stakeholders who are deemed enemies of the group (e.g., the use of marching songs in armies, Kluver et al. 2014). The second theme is that corporate singing may be useful to encourage members to reach out to and recruit others into the focal group (El-Sawad and Korczynski 2007; Nissley et al. 2003). The third theme is that corporate singing may foster mutual understanding with and among people beyond the singing group (e.g., Brooks 2010). As we explain below, a key issue 
that may distinguish between these three potential outcomes is the type of corporate singing evident in the organization.

\section{Types of organizational culture and types of corporate singing}

In order to examine the relationships between different types of organizational culture and different types of corporate singing, our study draws on the Competing Values Framework (Quinn and Rohrbaugh 1983), which describes four types of organizational culture that are created by combining the two fundamental dimensions of organizational culture: internal integration and external adaptation (Schein 1985). The first dimension examines the internal versus external components, and suggests an organization's culture tends to emphasize either an internal focus (i.e., prioritizing stakeholders inside the organization) or an external focus (i.e., prioritizing stakeholders outside of the organization). The second dimension distinguishes organizations based on how much they value integration (i.e., stability and predictability) versus adaptation (i.e., flexibility and change). As shown in Figure 1, crossing these two dimensions yields four different types of culture: 1) a hierarchy culture values stability and an internal focus; 2) a market culture values stability and an external focus; 3) a clan culture values flexibility and an internal focus; and 4) an adhocracy culture values flexibility and an external focus. This $2 \times 2$ Competing Values Framework has been empirically validated (e.g., Cameron and Quinn 2006; Howard 1998), is the most widely used typology in the literature on organizational culture (e.g., Graafland 2018), and has been used successfully to examine religious organizations (e.g., Boggs and Field 2010).

-- insert Figure 1 about here --

We hypothesize that these four types of organizational culture will be associated in predictable ways with a simple typology of singing that can be developed based on the three key 
elements of (Western) music: rhythm, melody, and harmony (Martineua 2008; Scruton 2011). These three musical elements are most clearly evident in three key types of corporate singing: chanting, unison, and harmony. Below we explain the rationale for hypothesizing that corporate singing that emphasizes: a) rhythm through chanting will be related to the hierarchy culture, b) melody in the form of unison singing will be related to the market culture, c) harmony singing will be related to the clan culture, and d) a mixture of types of singing (e.g., harmony and unison) will be associated with the adhocracy culture.

\section{Chanting and hierarchy culture}

Rhythm, the first element of music, refers to the arrangement of sounds such that there is a patterned variation between weak and strong sounds in a way that propels the music forward. Rhythm invites participants to sway to the music, as in dancing to the beat of a song (Scruton 2011). Rhythm is particularly effective at enabling coordinated movement among people at work, worship, and recreation (Scruton 2011). Rhythm generates a sense of community as people permit themselves to be governed by the shared-in-common rhythmic stimulus (Scruton 2011). As a result, rhythmic music is especially good at bringing about a sense of unity and order (Luhrs 2015).

Rhythm is an element found in all corporate singing, but chanting is a form of singing where the emphasis on rhythm is front-and-center (Graham 1996). There are many variations of chanting, but the term typically refers to a rhythmic recitation or repetitive singing of words and phrases, typically using several main pitches called reciting tones. For example, sports fans may chant "Go [insert team nick-name here] go" or "Let's go [insert team nick-name here] let's go". Other examples include Chinese chanted poetry, chanted mantras in Hinduism, and Hawaiian 
chants. In this paper, the term chanting includes any singing that places primary emphasis on the musical element of rhythm (e.g., including cadence or marching songs).

Likely the best-known example of rhythmic corporate singing in the business world is the Walmart chant, though similar company chants are evident in organizations around the world (e.g., including the Chinese firm Fuyao, depicted in the documentary American Factory). The rhythmic element of music is likewise emphasized in the cadence and marching songs sung by armies. For example, the famous marching song popularly known as "Sound off" is actually called the "Duckworth chant" (Schoonderwoerd 2011).

Military chanting is a particularly informative example. It has been noted that armies spend hours practicing marching drills even though marching to the Duckworth chant does not help soldiers learn military maneuvers that they will use in battle. Rather, chanting serves to weaken the boundaries between the self and the group (Kluver et al. 2014). As such, armies may use chanting to create malleable soldiers who will obey commands from officers (Wiltermuth and Heath 2009). Similarly, in corporations like Walmart and Fuyao, the goal of chanting may be to heighten employee energy, motivation, loyalty, and productivity (e.g., Maxwell, 2008). Thus, chanting appears to have an internal focus (e.g., connecting members to one another, following a common leader, and distinguishing the group from external stakeholders), and an emphasis on creating stable, repetitive, and predictable rhythms within organizational life. These two dimensions define the hierarchy organizational culture.

Hypothesis 2: Corporate chanting is associated with the hierarchy organizational culture. Singing in unison and market culture

The second musical element, melody, refers to an aurally-satisfying sequence of a variety of rhythmically-arranged individual pitches (i.e., musical notes) as a song unfolds from 
beginning to end. In order to give attention or weight to the melody of a song, it is typically sung in unison and given greater emphasis than the rhythm (e.g., popular music, folk songs, national anthems). Just as chanting's focus on the rhythmic elements of music is enhanced by having a simple (rather than ornate) melody, so also a feature of emphasizing melody is that such songs are often sung in unison in order to avoid the distraction that comes from many-voiced harmony (Scruton 2011). Singing in unison connects people together in the same way that chanting does, but adding a stronger emphasis on melody draws attention to -- and thereby strengthens -- the explicit message of the song as expressed in its lyrics (but also the implicit message that participants are part of a united group with a powerful message).

Company songs often involve new lyrics sung in unison to "the tune of" a melody from an existing popular song (e.g., El-Sawad and Korczynski 2007). This reuse of popular tunes emphasizes the message in the lyrics, insofar as the new words become the most salient element of the previously familiar music. Prototypical organizational examples of corporate singing in unison include Japanese firms that have a company song (e.g., Suzuki 1985), businesses with a corporate anthem (e.g., Lapshin, Mukhamedzhanova and Kosorukova 2016), and the protest songs associated with labour unions (Denisoff 1996). Note how all of these examples of corporate singing in unison, in addition to fostering solidarity with one's group, also serve to differentiate the organization from other groups (e.g., other companies' songs, other nations' anthems, management versus labour). Unlike corporate chanting, which tends to have an inward focus, corporate singing in unison often seeks to persuade external stakeholders of the merits of the focal organization. This sort of persuasion is evident in examples such as singing the national anthem of the gold medal winner at the Olympics, singing protest songs in solidarity on the picket line, and when social activists sing messages calling for peace. 
IBM provides a helpful example. As described by El-Sawad and Korczynski (2007), IBM had a strong emphasis on unison singing from the 1930s through to the 1970s. In 1931, IBM founder Thomas Watson Sr. published "The Songs of the IBM," a collection of over 100 songs about IBM written by employees. These songs were taught to new recruits, and employees regularly sang them at IBM meetings and events. Two key observations emerge when examining these songs. First, over 80 percent of the songs were in the form of traditional musical genres that reinforce uniformity and group identity, such as folk songs, marching songs, and anthems. Second, the songs had a very strong emphasis on the superiority of IBM products (evident in 65 songs, by far the most dominant theme). This emphasis signalled not only pride in the company (and that there was no need for IBM to change), but also contained an outreach component (over 30 songs had an emphasis on sales) that has been described as "evangelical." Indeed, "evangelism" was one of the four themes that El-Sawad and Korczynski (2007) identified in the songbook's lyrics (along with sales, work ethic, and paternalism). Similarly, and also describing their "evangelistic fervor," regular corporate singing at company events "played a powerful role in uniting and motivating a sales force, unparalleled in the home appliance industry" at Maytag in the 1920s and 1930s (Nissley et al. 2003, 100).

As these examples suggest, unison singing aligns well with an emphasis on stability and predictability. Like the regular rhythmic music in chanting, singing in unison nurtures predictability and stability among corporate singers. In both chanting and unison, corporate singers are encouraged to sing in "one voice" (Gillespie 2016), and being united in rhythm and melody creates a sense of security, order, and stability, which in turn fosters loyalty to the group and its traditions. Indeed, by adding the musical element of melody to rhythm, corporate singing 
in unison may create a heightened feeling of order and unity, thanks to its increased emphasis on the lyrical message of the songs.

However, in contrast to the self-regard of rhythmic singing, a focus on unison singing appears to foster an attitude of outreach, on proclaiming the singular merits of the organization to attract new members and customers. For example, the revival of Japanese company songs has been spurred in part by reasons of outreach and marketing: posting a video on-line of members singing their company song enables a firm to stand out from the crowd of competitors (e.g., Head 2004). Corporate singing at IBM and Maytag similarly had a significant component of evangelical outreach. Corporate singing in unison connects people together in the same way as chanting does, but it adds greater emphasis on the melody and thereby the common message of the group, and in doing so appears to generate greater conviction and power to proclaim that message to the world. The emphasis on a message shared in one voice strengthens uniformity and stability, while at the same time fostering a desire to share this powerful message with others. These are hallmarks of the market organizational culture.

\section{Hypothesis 3: Unison corporate singing is associated with the market organizational} culture.

\section{Singing in harmony and clan culture}

Harmony occurs when singers in a choir produce two or more pitches simultaneously that are heard as a single sound (Scruton 2011). These two or more pitches typically represent different notes of a musical chord, and Western choirs often sing in four-part harmony: soprano, alto, tenor, and bass. Historically, the element of harmony developed after rhythm and melody (Begbie 2017), with the latter two elements almost always evident in four-part harmony choir songs. In this way, the three elements of music share a similarity with the Competing Values 
Framework approach to organizational culture, which also states that elements of all four cultures are often evident in every firm, but the cultural type associated with one combination of those elements will most frequently and influentially characterize the firm (e.g., Quinn 1988).

Compared to chanting and unison singing, a distinctive feature of singing in harmony is how it facilitates mutual understanding and a sense of collectivity. Indeed, "working in harmony" is a common metaphor for ideal interpersonal relationships in the workplace (e.g., Luhrs 2015; Faulkner and Davidson 2006). Corporate harmony singing is more attuned to, and welcoming of, diversity and change than chanting or unison singing, in three ways. First, chanting and singing in unison seek to have members sing in one voice, singing the same note as the others (e.g., singers who do not fit in with the "one best note" are not welcome). In contrast, in corporate harmony singing, not only are different voices welcome, they are required. Thus, harmony singing values diversity and variety. Harmony singers will be literally more attuned to a variety of voices, and focus on the larger group or community as whole, rather than on individual voices or pitches (Morton 2001). Second, in chanting and unison singing all the voices move in lockstep, simultaneously going up or down in pitch at the same interval and time. In contrast, in harmony singing the different voices often move in different directions and at different intervals (e.g., the soprano line may move up in pitch at the same time that the bass line moves down). Moreover, this moving in different directions does not always happen at the same time for different voices, such as when some voices (e.g., tenors) sing only one note while others (e.g., sopranos) sing various notes, and a third voice (e.g., alto) sings two notes. Finally, whereas improvisation is typically not encouraged in chanting and unison singing, in corporate harmony singing choir members may be encouraged to harmonize in ways that are not on the song sheet, and they may be complimented (and complemented) by other choir members for their innovative 
runs, rather than chastised for straying from the written music (Faulkner and Davidson 2006). Janson (2018) argues that when members of a workplace choir experience and relish such mutual change and adaptation during singing, it facilitates organizational learning and change, because the experiences in the choir are embedded in the everyday life of the larger organization.

In addition to highlighting the relatively change-oriented character of singing in harmony, the three characteristics described above also suggest how singing in harmony can foster an internal focus. In particular, singing in harmony fosters an internal focus because it demands that each member use their voice in a way that is attuned to, fits with, and complements the other voices. Singers get to know themselves more fully as individuals different from others, but always in relation to and in a dynamic interdependence with the other singers (Faulkner and Davidson 2006). Consistent with this internal focus, studies of workplace choirs describe the sense of "community from diversity" created by singing in harmony in workplace choirs:

"the sense of community did not arise from having the same opinion, singing the same part or being at an equal level of competence. Community in fact arose from simply engaging in the choral practice. ... When singing with the boss on equal terms, and seeing him in a non-hierarchical position in the choir, a sense of unity was created" (Balsnes and Jansson 2015, 13; see also Carter 1954).

The unity associated with singing in harmony fosters a dynamic sense of internal integration, in contrast to the stable internal integration associated with chanting. Singers work together within the organization as a united team that is able to sing in harmony, where each voice is different and recognized as important and necessary. A similar point is made by one of the participants in Jansson's (2018) longitudinal study of a small company choir: 
"if you come out of the basement [choir practice] and have been singing in perfect harmony and performed a really good tune, you simply cannot go up to the top floor and have a bad meeting. [...] You cannot yell at someone you've had a fantastic choir rehearsal with" (Jansson, 2018, 9).

Taken together, these and other studies (reviewed in Gick 2011) suggest that groups singing in harmony combine an internal focus with an emphasis on change and adaption, which are the distinguishing features of a clan culture.

\section{Hypothesis 4: Corporate singing in harmony is associated with the clan organizational} culture.

In addition, recall that Hypothesis 1 suggests that the effect of singing on prosocial behavior is higher for organizations where people participate in corporate singing, rather than merely listen to singing. This difference suggests that the greater the level of engagement with music, the greater its effect on participants. One potential extension based on this difference would be to suggest that the greater the engagement with the musicality of corporate singing, the greater its effect on participants. Just as singing is more engaging than listening, so also singing challenging music may be more engaging than singing simple songs.

There is some agreement that the musicality of singing in harmony is greater than that of singing in unison or chanting (e.g., Faulkner and Davidson 2006; Martineau 2008; Scruton 2011), and that it engages more parts of the brain (Brown, Martinez, Hodges, Fox and Parsons 2004). Singing in harmony requires attending both to rhythm and to singing in unison with some of the others voices in a choir (e.g., altos sing in unison with other altos), plus singing different notes from others (e.g., sopranos sing different notes than altos), and sometimes with differing timing. Indeed, precisely because singing in harmony is more challenging musically, there are 
efforts in some religious organizations to replace singing in harmony with singing in unison so that more people can participate (e.g., Faulkner and Davidson 2006).

In addition to being more demanding and thus potentially more engaging musically, it seems reasonable to suggest that the distinct characteristics of singing in harmony described above will further help to foster prosocial behavior. By requiring, welcoming, and being attuned to a variety of voices, corporate harmony singing may predispose members to be attuned to and respond to the needs of a variety of people (perhaps especially marginalized voices, Brooks 2011). In addition, corporate singing in harmony encourages members to use their voice in new ways, while simultaneously seeking ways to bring out the best in others. This behavior could generalize to other situations, leading organization members to seek to help others to be better.

Hypothesis 5: Corporate singing in harmony facilitates greater pro-social behavior than other types of corporate singing.

\section{Mixing types of singing and adhocracy culture}

Sometimes organizations may emphasize a mix of types of singing - for example, sing some songs in harmony, others in unison, and yet others chanting - rather than focus on one type of singing. Note that mixing the three different types of singing is qualitatively different from the combination of all three musical elements evident in harmony. Harmony has elements of rhythm and melody, but its relative emphasis is on harmony; melody and rhythm are important, but subsidiary, musical elements. In contrast, in a mixed approach to corporate singing, the three different types of singing each take turns as the focal point. For example, an organization may choose to sing in harmony when seeking to foster team-building or mutual understanding (Hypothesis 4), may engage in corporate unison singing to promote activities related to outreach (Hypothesis 3), and may chant when emphasizing unity (Hypothesis 2). 
There can be many different variations within the mixed approach. Some organizations might seek to balance all three types of corporate singing, while others may use only two, and their use may not be balanced. In some cases, there may be different members involved in the different types, such as the Walmart chant being performed by everyone in the organization, while only the subset of members who participate in a workplace choir sing in unison or harmony. For present purposes these variations are all examples of mixed corporate singing, in that they differ from an organization that focuses mostly on only one type of singing.

A mixed approach may represent a strategic decision to try to adaptively be "all things to all people," or it may represent an organization in transition from one type of singing to another. In both cases, we suggest that the mixed approach has its primary focus on external adaption, changing the type of corporate singing to reflect the situation facing the organization. While this may offer certain strategic advantages, it fails to take full advantage of any one of the three types of singing. This is consistent with the adhocracy culture, where organizations seek to balance multiple goals simultaneously, even if doing so means failing to master any of them (Quinn, 1988, 36). An adhocracy culture also has an emphasis on external adaptation, on being all things to all people.

Hypothesis 6: Mixing types of corporate singing is associated with the adhocracy organizational culture.

\section{Method}

\section{Sample}

Since the study of corporate singing is quite nascent, we sought to test the hypotheses among a population of organizations where the phenomenon of interest would be most prevalent and transparently observable (Edmondson and McManus 2007; Eisenhardt 1989). Specifically, 
we chose to focus on religious organizations, based on their historical and contemporary emphasis on singing. We collected data from religious organizations in one large mid-western city, seeking to ensure that our sample would include organizations from all the different religions and denominations in that location. Seventy-four religious organizations that serve as local meetings places of worship for adherents provided data; however, one organization indicated that music played no significant role, and thus was dropped from the analysis. The remaining 73 organizations represented 17 distinct religious groups. Our survey instrument was completed by a leader from each organization.

\section{Measures}

\section{Corporate listening versus corporate singing}

We asked respondents: "What style of singing characterizes your organization? (check all that apply)." The largest number of respondents indicated "solos" $(\mathrm{N}=26)$, which represented our measure of "corporate listening" in organizations, since solo singing, by definition, excludes most participants, causing the organization to emphasize music listening more than music making. The remaining $(\mathrm{N}=47)$ organizations were categorized as "corporate singing," based on their engagement in: "liturgical (e.g., chanting)" ( $\mathrm{N}=8)$; "unison" ( $\mathrm{N}=12)$; "4-part harmony" $(\mathrm{N}=5)$; or more than one of these three types of singing $(\mathrm{N}=22)$.

\section{Prosociality}

We used two separate measures related to prosocial behavior and values. The first measure concerned prosocial behavior within the organization, and examined the prevalence of volunteering within the organization. It was common for organizations in our sample to have five or more committees that needed to be staffed by volunteers within the organization, addressing issues such as planning weekly meetings (e.g., worship committee), children's programming, the 
needs of specific demographic groups (e.g., young adults, older members, men, or women), community service, property and finance, nominating, and so on. It was not unusual for some religious organizations to have a difficult time finding volunteers to fill all of these positions. To assess prosocial behavior through voluntarism, our survey asked a dichotomous question: "Generally speaking, do most members take their turn serving as volunteers in the local organization [1 = high prosocial], or does the same subset of people end up doing most of the work most of the time $[0=$ low prosocial $] ? "$

The second measure examined the values of the organization related to prosocial behavior extended outside of its boundaries. We measured prosocial values in terms of resolving conflict in ways that develop mutual understanding, consistent with the literature linking prosocial behavior to singing in social activism and the peace movement (e.g., Begbie 2011; Brooks 2010). The survey item presented a 5-point Likert scale regarding the values taught by their religious tradition: "The use of violence to resolve conflict: may be justifiable [ $1=$ low prosocial], is always wrong [5 = high prosocial $]. ”$

\section{Organizational culture}

We operationalized organizational culture using two different approaches. The first approach provided a description of four different hypothetical organizations, where each description represented one of the four organizational culture types associated with the Competing Values Framework. Respondents were asked to complete an ipsative measure: “Of the four types of organizations described below, which is/are most consistent with your religious values? Allocate 100 points among the four options below:"

_ _ [clan culture] "Our local organization should be like Organization A, a tight knit family characterized by teamwork, consensus decision making, and participation." 
__ [adhocracy culture] "Our local organization should be like Organization B, constantly search for new ways to do things where people feel accepted and free to initiate unique and innovative ideas."

_ _ [hierarchy culture] "Our local organization should be like Organization C, a place where members feel secure, have a strong understanding of their religious foundation, and tradition is highly valued."

_ _ [market culture] "Our local organization should be like Organization D, an outward looking organization where people are encouraged to work hard towards organizational goals and provide an example for people outside the organization."

Note that a high emphasis on the organizational culture found in any one of the four quadrants in the Competing Values Framework, as depicted in Figure 1, should correspond to a low emphasis in the diagonally opposite quadrant. For example, we would expect an organization that is most like a hierarchy culture $(\mathrm{OrgC})$ to be least like an adhocracy culture $(\mathrm{OrgB})$, and an organization that is most like a market culture $(\mathrm{OrgD})$ to be least like a clan culture (OrgA). Thus, the points respondents assigned to the diagonally opposite quadrant provide additional information about the likelihood that the focal quadrant is the dominant culture. With this in mind, we calculated a net score for each of the four types of culture, by subtracting from the focal culture the points the respondent assigned to the diagonally opposite culture. For example, if a respondent assigned 35 points to clan culture (OrgA) and 5 points to market culture (OrgD), then the net score for clan would be 30 points and the net score for market would be -30 points. And if a respondent assigned 20 points to clan culture and 20 points to market culture, the net score for each would be 0 points. In this way, in our analyses we 
compared the difference between OrgA and OrgD, and OrgB and OrgC. We called this the "net culture" score.

The second approach to measuring culture directly assessed aspects of each of the two dimensions underlying the Competing Values Framework. The first dimension of organizational culture concerns the emphasis that an organization places on stability and integration, versus change and adaptation. To assess this relative emphasis on change vs. stability dimension, respondents used a 5-point Likert scale to respond to the following: "Would you describe your organization's worship 'style' as: "innovative" $(1=$ change $)$ versus “traditional” ( $5=$ stability $)$.

The second dimension, relative emphasis on internal vs external focus, was measured using an item in which respondents indicated their success at recruiting people from the external environment into their organization: "Were the majority of members in your local organization raised by parents who shared the same faith, or were they raised by parents who had a different, or no, faith:" "same faith" (1 = internal), versus "different faith" $(2=$ external $)$.

We wanted to test whether, compared to the other types of corporate singing, each one of the four types of singing was associated with the hypothesized pole of each of these two dimensions (i.e., change vs stability, internal vs external). For example, we hypothesized that mixed corporate singing and harmony would be more change-oriented, and that chanting and unison be more stability-oriented. Thus, for each test we used the data from three types of singing: we compared the focal type of singing to the two types of singing that were predicted to be on the opposite end of the dimension being tested. For example, we tested whether mixed corporate singing was more change-oriented than chanting and unison, and then we tested whether harmony was more change-oriented than chanting and unison. 


\section{Control variables}

All hypothesis tests included two control variables: organization age and size. Age referred to how long the organization was in existence, and size referred to the number of active adults involved in weekly programs of activities. As organization grow in age and size, they tend to become more formalized and bureaucratized (e.g., Donaldson 1999), which is associated with the hierarchy culture.

\section{Results}

Our sample comprised 17 different religious groups: Adventist, Alliance, Anglican, Bahai, Baptist, Catholic, Jehovah Witness, Jewish, Latter-Day Saints, Lutheran, Mennonite, Muslim, non-denominational, Orthodox, Presbyterian, Salvation Army, and United Church of Canada. The age of the organizations ranged from 3 years to 165 years (average 51). The number of active adults ranged from 0 (this organization comprised 14 youth) to 1,400 (average 220). The number of years the current leader was in that position ranged from 1 year to 52 years (average 7). The number of activities planned per week ranged from 1 to 20 (average 9), and on average members attended 1.6 activities per week.

Hypothesis 1 predicted that organizations where members sing, compared to those where members only listen to singing, would display more prosocial behaviors and values. Our results were mixed. In terms of prosocial volunteer behavior, a significantly larger proportion of organizations with corporate singing benefitted from widespread volunteer support than did than those with corporate listening (.43 vs $.15, p=.02)$. In contrast, there was no significant difference in terms of prosocial values toward others in the two groups (mean 3.70 vs 3.27, $p=$ .17). Hypothesis 1 thus received partial support. 
Hypothesis 2 predicted that among organizations with corporate singing, those that emphasized chanting would have a stronger association with the hierarchy organizational culture, compared to other kinds of singing. Again, the results were mixed. In terms of our ipsative-based measure of overall culture, chanting organizations' tended to have a greater emphasis on hierarchy $($ Welch $t=2.01, \mathrm{df}=12.79, p=.07)$. However, counter to Hypothesis 2 , chanting organizations' emphasis on stability was not significantly different from that of organizations with harmony or mixed singing (mean 3.87 vs $3.15, p=.15$ ). Finally, consistent with Hypothesis 2 , chanting organizations were somewhat less likely to report an external focus in terms of recruiting, compared to organizations with unison or mixed singing (.00 vs $.38, p=.06)$. Hypothesis 2 received provisional partial support.

Hypothesis 3 predicted that corporate singing organizations that emphasized unison singing would have the strongest association with the market organizational culture. In terms of the ipsative market culture score, the results did not support this prediction $($ Welch $t=1.72, \mathrm{df}=$ $10.59, p=.11$ ). Similarly, unison singing organizations' emphasis on stability was not significantly different from that of organizations with harmony or mixed singing (mean $3.08 \mathrm{vs}$ $3.15, p=.98)$. Moreover, although unison singing organizations had a higher proportion reporting an external focus in terms of recruiting, the difference was not statistically significant compared to organizations with harmony or chanting (.42 vs $.00, p=.99)$. Hypothesis 3 was not supported.

Hypothesis 4 linked an emphasis on harmony singing with the clan organizational culture. The ipsative clan culture score provided marginal support for this association (Welch $t=2.18, \mathrm{df}$ $=5.52, p=.08)$. In contrast, there was no significant difference in harmony organizations' emphasis on stability compared to that of chanting and unison singing (mean $2.80 \mathrm{vs} 3.40, p=$ 
42). However, harmony organizations had a marginally significantly lower proportion reporting an external focus in terms of recruiting relative to unison and mixed singing organizations $(.00 \mathrm{vs}$ $.38, p=.06)$. Hypothesis 4 was partially supported.

Hypothesis 5 predicted that harmony singing organizations would have more prosocial behaviors and values than other singing organizations. In terms of behavior, a larger proportion of harmony organizations reported prosocial volunteering than did other organizations (.80 vs $.38)$, and the difference was marginally significant $(p=.10)$. Regarding external prosocial values, the mean score of harmony organizations was significantly higher than that of other organizations (mean 5.00 vs $3.57, p=.03$ ). The results were generally consistent with Hypothesis 5.

Hypothesis 6 linked the use of mixed singing with the adhocracy organizational culture. The ipsative adhocracy culture score provided marginal support $($ Welch $t=1.74, \mathrm{df}=38.44, p=$ .09). However, there was no significant difference in mixed singing organizations' emphasis on stability compared to that of chanting and unison singing (mean 3.23 vs $3.40, p=.64$ ). Likewise, mixed singing organizations were not significantly more likely to report an external focus in terms of recruiting relative to chanting and harmony singing organizations (.36 vs .00, $p=.99$ ). Hypothesis 6 received little support.

\section{Discussion}

Like all studies exploring new theory, this one paves the way to asking better questions, both in terms of which questions to ask and how to ask them. At the most general level, the findings suggest that there is merit in further research looking at the link between corporate singing and prosocialty, and between corporate singing and organizational culture. In particular, the results related to the ipsative measure of organizational culture indicated three of the four 
types of corporate singing were related to organizational culture as predicted $(p<.10)$. This result is consistent with the fact that music has been an integral part of culture for most of the history of humankind, and that we may be missing something important by overlooking it in organizational scholarship. Indeed, there seems to be growing interest in corporate singing among practitioners, and some management scholars are calling for more research that looks at music in organizations (e.g., Jackson 2017; Meyer 2019). Below, we focus on the implications of our findings related to corporate singing and prosociality, organizational culture, and spirituality, and we discuss limitations of our study.

\section{Corporate singing and prosociality}

Our findings provide some support indicating that corporate singing may be related to greater prosociality than listening to music (Hypothesis 1). We also found good support for the prediction that corporate harmony singing is related to greater prosociality than other types of corporate singing (Hypothesis 5). Together, the results suggest that there is a link between music-making and organizational prosociality, and that the greater the engagement the stronger the link. This result is of no small importance, given the growing evidence of negative effects on social well-being arising from practices based on mainstream economic and management practice (e.g., Ferraro et al. 2005). While it would clearly be an overstatement to suggest that corporate singing can solve all our problems - the proverbial word-picture of singing Kumbaya holding hands around a campfire comes to mind — our research does suggest that singing might nudge organizational members to become more prosocial. That in itself is a result worthy of further pursuit, perhaps especially if the prosocial behaviors spill beyond the boundaries of the firm and influence how it deals with social and ecological externalities. 
Others have noted that music can serve as an intervention to facilitate culture change (e.g., Giaver et al. 2017; Schein 1985). By connecting people to one another, corporate singing can break down barriers between people, and provide opportunities to make organizational changes that nurture social well-being. This potential raises a series of questions worthy of future research. For example, beyond being associated with prosociality in general, does corporate singing facilitate the development and implementation of prosocial organizational strategies? Further, does it make a difference whether the group members participating in corporate singing are only formal strategy makers, or if it includes members from all parts of the organization? What might happen if customers, or neighbors, or homeless people were added to the workplace choirs (see Moss and O'Donoghue 2018)? Can workplace choirs decrease pay dispersions within an organization, increase appreciation of diversity within the workplace, enhance corporate social responsibility, reduce job-related stress, and increase corporate citizenship behaviors (e.g., Cook 2017; Werber 2019)? Does corporate singing, in addition to making participants more likely to exhibit prosocial behavior, also make them more competent working together with others (e.g., Valdesolo, Ouyang and DeSteno 2010; see also Meyer 2019)? In short, the study of corporate singing has implications for a wide range of organizational issues and scholarly fields.

What about possible "dark sides" of corporate singing (e.g., Morris 2010)? Can singing create a stultifying culture (e.g., Luhrs 2015)? History suggests that unison singing may be particularly vulnerable to manipulation as a political tool, as is evident in the thousands of people who sang together at Hitler's political rallies, and the importance of singing in unison in other fascist regimes (e.g., Kagan and Kirchberg 2016; Lidtke 1982; Turino 2008). El-Sawad and Korczynski (2007) speculate that the powerful combination of loyalty and fervor that may be evoked by corporate singing may have been what prompted IBM to destroy every copy of its 
songbook in the 1970s, perhaps recognizing how music has been (mis)used for unsavory purposes. Can corporate singing be used in ways that create hostility and enmity, in ways that widen the gap between employees and managers? What are the hallmarks of such use, and what are the safeguards to prevent it?

\section{Types of corporate singing and organizational culture}

Even though our results provide only modest support for our specific hypotheses regarding the relationships between types of corporate singing and organizational culture, we believe that they provide a valuable springboard and conceptual foundation for future research. Our findings provide at least some evidence of relationships between corporate chanting and the hierarchy organizational culture (Hypothesis 2), between corporate harmony singing and the clan culture (Hypothesis 4), and between mixed singing and the adhocracy culture (Hypothesis 6). However, there was no support for the relationship between unison singing and the market culture (Hypothesis 3). Moreover, none of the four types of singing had the expected relationship with our measure of organizational change propensity, though several did show the expected association with our measure of reaching out to the external environment.

Although our findings are modest, in light of the exploratory nature of our study and its shortcomings, we believe that they provide a welcome contribution and impetus for future research examining links among types of corporate singing and organizational culture. Ours is the first study we are aware of to use a population of organizations to examine corporate singing (previous research has tended to use case studies of one or several organizations; e.g., Giæver 2019; Van As 2010). It was also the first designed to examine and compare different types of corporate singing, and the first to explore possible links between different types of singing and 
different types of organizational culture (called for by scholars like Gick 2011, Gillespie 2018, and Jeffery 1995).

Apart from pointing to links between corporate singing and both prosociality and organizational culture, perhaps the most important potential contribution our study makes is to provide a conceptual framework — based on the three mains types of corporate singing — that can be applied, refined, and used in future research. As shown in our literature review, others studying corporate singing and its effects often do not mention (or are unaware) that the particular type of singing they are studying may have unique effects. Occasionally studies suggested that there may be differences between singing in unison and harmony, but even then the expected differences or reasons for the differences were under-developed (e.g., Brown et al. 2004; Faulkner and Davidson 2006; Gick 2011; Morton 2001). Our approach and framework are unique insofar as they describe, explain, and predict differing social outcomes at the organizational level of analysis. Metaphorically, just like the Competing Values Framework has been useful to think about the different types of organizational culture, and the mechanisticorganic continuum has been useful for thinking about classical management and human relations (e.g., Burns and Stalker 1962: Donaldson 1999), so also our linking the different types of corporate singing to organizational phenomena represents a new way of understanding or seeing these phenomena (Poggi 1965). Our typology can be applied not only to research on organizational culture, but also to research using corporate singing as an intervention to facilitate organizational change in general (e.g., which type of song to sing for which situation?), and research that links corporate singing to different dimensions and expressions of prosocial behavior specifically (e.g., corporate social responsibility, corporate citizenship behavior, and cooperation). 


\section{Corporate singing and spirituality}

There is considerable agreement about the strong links between music and spirituality (Einarsdottir and Gudmundsdottir 2015; Guthrie 2003; Wlodarczyk 2007). For example, Aristotle believed that spiritual activity was one of the four functions of music (the other three functions were a means to overcome negative feelings, moral instruction, and relaxation; Einarsdottir and Gudmundsdottir, 2015). Wlodarczyk (2007) notes that music allows humans to express things for which words are inadequate, and thereby serves as a language to draw closer to a sense of the sacred. Scruton $(1997,502)$ argues that "through melody, harmony, and rhythm, we enter a world where others exist besides the self" (cited in Guthrie, 2003, 642).

Among the various expressions of music, corporate singing seems to be especially effective at facilitating spirituality, both because choir members actively participate in creating music (versus passively listening to it) and because adding lyrics (akin to good poetry) provides further opportunity to transcend linear, rational thought. Indeed, people singing in choirs recognize its spiritual benefits (Clift and Hancox 2001; Einarsdottir and Gudmundsdottir 2015; Livesey et al. 2012; Moss 2019), perhaps because it facilitates connectedness with others and leads to transcending boundaries between 'self' and 'other' (Dingle et al. 2013; Fischer et al. 2013; Kluver et al. 2017; Mellor 2013). This self-transcendence may be related to the observation that corporate singing requires singers to be in the moment, to have a relational consciousness that includes others, and to be attuned to something outside of oneself, all while experiencing a sense of flow (Mellor 2013). Social activists and religious organizations draw particular attention to the spiritual, social connectedness, and emotional elements of corporate singing, in ways that transcend the effectiveness of mere speech (Sanger 1997; Wald-Fuhrmann et al. 2020). 
Indeed, corporate singing can be considered to be a literally spiritual activity, insofar as the word "spirit" comes from the Latin word spiritus meaning "breath." When people sing together, they literally breathe together in rhythm, which can contribute a sense of self-transcendence (Hayward 2014; Kennedy 2009; Stepanova et al. 2020). In this way, a choir can be seen as becoming of one breath, or of one spirit.

Building on our study, future research might examine whether the three musical elements in corporate singing — rhythm, melody, or harmony —are related to different dimensions of spirituality. Such research would require a multi-dimensional understanding of spirituality, such as the one developed by Liu and Robertson (2011) whose construct of spirituality has three distinct factors: a sense of interconnectedness with a higher power, with other people, and with nature. There is good reason to believe that corporate singing may be associated with corporate spirituality generally (e.g., Clift and Hancox 2001; Dingle et al. 2011; Einarsdottir and Gudmundsdottir 2015; Hayward 2014; 2020; Livesay et al. 2012; Moss 2019; Kennedy 2009; Stepanova et al. 2020). However, it remains to be determined whether or how the three elements of music may be related to the three dimensions of spirituality. As described below, we suspect such relationships may exist.

First, regarding the relationship between music and nature, it has been noted that an improbable proportion of environmentalists also are part-time musicians (Berger 1978). We believe this link is not a coincidence, so it is worth investigating. In particular, we wonder whether corporate singing that emphasizes rhythm (e.g., chanting) may be particularly effective at developing a sense of connectedness to nature (Liu and Robertson 2011). It has been argued that chanting can facilitate connectedness to nature via a sense of entrainment (Hayward 2014; Norris 2018). Entrainment occurs when self-sustaining rhythmical systems synchronise with 
each other, such as when chanting choir members' breathing and heart rates synchronise with each other (Hayward 2014; Müller and Lindenberger 2011). In addition to connecting with other humans, in many spiritual traditions the entrainment associated with chanting has a focus on connecting to the natural world and its rhythms. For example, Dudeja $(2017,22)$ argues that the "Om" sound associated with many kinds of chanting is most effective when it vibrates at a frequency of $136.1 \mathrm{~Hz}$, which is related to "the vibrational frequency found throughout everything in nature" including the rhythm of the earth's annual orbit around the sun:

"Everything in the universe is pulsating and vibrating - nothing is really standing still! 'Om' is said to be the original, primordial tone of the universe - the original sound of creation, if you like. It is interesting to note that the astrophysicists have now detected echoes of the "Big Bang" that happened at the beginning of time. And this sound they have detected is a humming sound, very much like that of the 'Om."'

When one realizes that everything is vibrating (i.e., that rhythm is a key characteristic of the natural world and reality), then chanting can be seen both as a way connecting with, and a way of knowing, reality and wholeness (Norris 2018). For example, Nichiren Buddhist chanting is thought to bring people to a higher state of consciousness that entrains them in harmony with rhythms of life and laws that govern the universe (Hayward 2014).

Second, researchers may examine whether corporate singing that emphasizes melody (e.g., singing in unison) is particularly relevant for the second dimension of spiritualty, namely that of developing a sense of connection to a higher power. Connecting with the sacred depends on awareness that there is something that transcends the human and natural world, or perhaps more accurately, that the human and natural world are part of something larger (Liu and Robertson, 2011). Singing in unison can make people feel they are part of a larger, more powerful message, 
that goes beyond themselves, and even beyond their choir. By emphasising melody, singing in unison draws attention to the explicit message of the song as expressed in its lyrics, and thereby enhances the implicit message that participants are part of a united group. Singing in unison has been emphasized in some Christian traditions. For example, John Wesley (a leading figure in Methodism) emphasized the importance of congregations singing in unison (versus harmony): "strive to unite your voices together, so as to make one clear melodious sound" (Clarke 2009, 196). Another leader, Dietrich Bonhoeffer, urged Christians "to embrace unison singing above all other musical forms" because it allows singers to speak and pray at the same time (Guthrie 2003, 643). Bonhoeffer $(1954,41)$ suggested that: "It is the voice of the Church that is heard in singing together. It is not you that sings, it is the Church that is singing" (cited in Guthrie, 2003, 643). Singing in unison can transform singers into something larger than themselves in a way that is deeply connected to a higher power.

Third, as we have argued and found empirical support for in our study, corporate singing that emphasize harmony may be particularly effective at developing a sense of connection with others (e.g., Balsnes and Jansson 2015; Carter 1954; Faulkner and Davidson 2006; Jansson 2018). Consistent with this claim, a study of a choir that sang in mostly four-part harmony found that it had a spiritual impact on members, particularly in fostering a greater sense of social connectedness with others (both choir members and audience; Dingle et al. 2013). In part, this connectedness may reflect the need for people to listen to, and be attuned to, different voices in the choir (Brown et al. 2004). Harmony singers recognize that other voices are important, and that by singing their own voice well, they enhance others. This realization might encourage members to adopt attitudes consistent with the prosocial hallmarks of connectedness to other people (Liu and Robertson 2011). 


\section{Limitations and future research}

Ours was a first, exploratory study and thus suffered from limitations associated with the nascent nature of the research area. These limitations highlight directions and opportunities for future work. For one, our measures of types of singing and types of culture were very coarsegrained. As such, we would encourage future research to ask more detailed questions in terms of type of music being sung, and especially to look at why some types of music are being sung on which occasions. These variations may be especially important for corporate singing that uses a mixture of types. For example, consistent with our hypotheses, is chanting being used intentionally to build solidarity, unison for outreach, and harmony for team-building? Research could also include measures of the effect on participants as they sing different types of songs (e.g., the effect on participants of singing harmony is discussed by Faulkner and Davidson 2006, and Winter 2009). Finally, research could incorporate an examination of the lyrics of songs (e.g., El-Sawad and Korczynski 2007; Nissley et al. 2003; Suzuki 1985), considering whether the message of the lyrics is consistent with the musical type of singing, and how those two elements interact.

Second, while the ipsative measure of organizational culture related to the Competing Values Framework was appropriate for an exploratory study, we would encourage future scholars interested in the Competing Values Framework to use a more advanced measurement tool with more items (e.g., Cameron and Quinn 2006; Howard 1998). That said, future research may also want to examine other models of culture and organizational values more generally (e.g., Cameron et al. 2004; Meyer 2019; Jackson 2017). Some of these other models or typologies may not put organizational culture front-and-centre, but rather in a more supporting role. This would be consistent with many of the configurational organizational theories and 
typologies, such as the well-known Defender, Analyzer, Prospector, and Reactor typology developed by Miles and Snow (1978). Thus, we see our study as a gateway not only for future research on the relationship between corporate singing and organizational culture and values, but also to relationships between corporate singing and other organizational elements which are related to culture and values.

Third, even though the sample size for our study was far greater than any other study on corporate singing at the organizational level of analysis, it was still much smaller than ideal to handle the statistical analyses related to our hypotheses. Related to this point, it also would be desirable to have more than one respondent per research site. Ideally, studies could conduct large-sample analysis based on multiple informants at different levels of the organization. Further, it would be good to visit each site to observe, or even participate in, the corporate singing, and to make observations related to organizational culture and other aspects of the organization (e.g., what kinds of musical instruments are included, how many song leaders).

Fourth, we purposely chose our sample to represent a wide variety of religious organizations in order to maximize the diversity in our data. However, other sampling opportunities remain for future studies. For example, if future researchers wish to continue the focus on religious organizations, attention can be devoted to examining how each faith community's unique history and practices influence the effects of corporate singing. Moreover, given the growing prevalence of singing in non-religious organizations, it would be informative to extend the study to them.

Finally, and perhaps most importantly, our study was not able to examine the direction of influence in the relationship between corporate singing and organizational culture. Future research using a longitudinal design could seek to determine whether, for example, corporate 
harmony singing prompts members to adopt a clan culture, or whether a clan culture prompts members to adopt harmony singing. Does music reside "at the center of culture" (Jackson, 2017, 24) or does culture drive musical choices?

\section{Conclusion}

The most important contribution of this study is not its specific findings or the questions it answers, but rather it is the questions and research agendas it can give rise to. We found evidence that different types of corporate singing may be related to different types of organizational culture, and thus opened the door for a range of future research examining music in organizations. We believe that the kinds of research questions prompted by our study are important and far-reaching. Metaphorically speaking, we invite researchers to work in harmony, possibly going in different directions, but always complementing one another in creating songs that enhance prosociality in organizations. 


\section{References}

Alvin, J. 1975. Music Therapy. New York, NY: Basic Books.

Anshel, A., and D. A. Kipper. 1988. "The Influence of Group Singing on Trust and Cooperation. Journal of Music Therapy, 25(3): 145-155.

Balsnes, A. H., and D. Jansson. 2015. "Unfreezing Identities: Exploring Choral Singing in the Workplace." International Journal of Community Music, 8(2): 163-178.

Begbie, J. S. 2017. "Modeling Harmony: Music, Theology, and Peace-Building." Interpretation, 71(1): 13-24.

Berger, B. (1978). "Science, Environmentalism, and Music." The North American Review, 263(1): 64-66.

Boggs, B., and D. Fields. 2006. “An Exploratory Study of Organizational Culture and Effectiveness of Christian Churches." In Academy of Management Proceedings, pp. E1E6. Briarcliff Manor, NY 10510: Academy of Management.

Bonhoeffer, D. (1954). Life Together (trans. John W. Doberstein). London: SCM.

Brown, S., M. J. Martinez, D. A. Hodges, P. T. Fox, and L. M. Parsons. 2004. "The Song System of the Human Brain." Cognitive Brain Research, 20(3): 363-375.

Brooks, J. R. 2010. “'Peace, Salaam, Shalom"”: Functions of Collective Singing in U.S. Peace Activism." Music and Arts in Action, 2(2): 56-71.

Burns, T., and G. M. Stalker. 1961. The Management of Innovation. London: Tavistock.

Busch, S. L., and M. Gick. 2012. "A Quantitative Study of Choral Singing and Psychological Well-Being." Canadian Journal of Music Therapy, 18(1): 45-61.

Cameron, K. S., D. Bright, and A. Caza. 2004. "Exploring the Relationships Between Organizational Virtuousness and Performance." American Behavioral Scientist, 47(6): 766-790.

Cameron, K. S., and R. E. Quinn. 2006. Diagnosing and Changing Organizational Culture: Based on the Competing Values Framework (rev. ed.). Reading, MA: Addison-Wesley.

Carter, E. 1954. "Singing Workers.” Journal of Research in Music Education, 2(1): 39-48.

Clarke, M.V. 2009. “John Wesley's 'Directions for Singing': Methodist Hymnody as an Expression of Methodist Beliefs in Thought and Practice. Methodist History, 47(4): 196209.

Clift, S. M., and G. Hancox. 2001. "The Perceived Benefits of Singing: Findings from Preliminary Surveys of a University College Choral Society. The Journal of the Royal Society for the Promotion of Health, 121(4): 248-256.

Couture, J. 2018. Let Them Hear Our Voices, Singing in Harmony: A Qualitative Case Study on a Workplace Choir. Master of Education dissertation, University of Saskatchewan.

Cross, I. 2006. "Music and Social Being.” Musicology Australia, 28: 114-126. 
De Avila, N. A. 2015. Effects of a Culturally Relevant Music Education Intervention on Choir Members' Attitudes toward Mexican Populations. Thesis, Master of Arts, University of Iowa.

Denisoff, R. S. 1966. "Songs of Persuasion: A Sociological Analysis of Urban Propaganda Songs." The Journal of American Folklore, 79(31): 581-589.

Dingle, G. A., C. Brander, J. Ballantyne, and F. A. Baker. 2013. "“To be Heard': The Social and Mental Health Benefits of Choir Singing for Disadvantaged Adults." Psychology of Music, 41(4): 405-421.

Donaldson, L. 1999. “The Normal Science of Structural Contingency Theory.” In Clegg, S. R. and H. Cynthia (Eds.), Studying Organization: Theory and Method (pp. 51-70).

London: SAGE Publications.

Dudeja, J. P. (2017). "Scientific Analysis of Mantra-Based Meditation and Its Beneficial Effects: An Overview." International Journal of Advanced Scientific Technologies in Engineering and Management Sciences (IJASTEMS-ISSN: 2454-356X), 3(6): 21-26.

Dunbar, R., K. Kaskatis, I. Macdonald, and V. Barra. 2012. "Performance of Music Elevates Pain Threshold and Positive Affect: Implications for the Evolutionary Function of Music." Evolutionary Psychology, 10(4): 688-702.

Durkheim, E. 1992 (orig 1887). "Review of Guyau's L'irreligion de l'avenir." In A. Giddens (Ed.), Emile Durkheim: Selected writings (pp. 219-222). New York: Cambridge University Press.

Durkheim, E. 1915. The Elementary Forms of Religious Life. London: George Allen and Unwin.

Edmondson, A. C., and S. E. McManus. 2007. "Methodological Fit in Management Field Research." Academy of Management Review, 32(4): 1246-1264.

Einarsdottir, S. L., and H. R. Gudmundsdottir. 2016. "The Role of Choral Singing in the Lives of Amateur Choral Singers in Iceland.” Music Education Research, 18(1): 39-56.

Eisenhardt, K. M. 1989. "Building Theories from Case Research.” Academy of Management Review, 14(4): 532-550.

El-Sawad, A., and M. Korczynski. 2007. "Management and Music: The Exceptional Case of the IBM Songbook.” Group and Organization Management, 32(1): 79-108.

Ehrenreich, B. 2006. Dancing in the Streets: A History of Collective Joy. New York: Metropolitan Books-Henry Holt and Company.

Eyerman, R., and A. Jamison. 1998. Music and Social Movements: Mobilizing Traditions in the Twentieth Century. Cambridge, UK: Cambridge University Press.

Faulkner, R., and J. W. Davidson. 2006. "Men in Chorus: Collaboration and Competition in Homo-Social Vocal Behaviour.” Psychology of Music, 34(2): 219-237.

Ferraro, F., J. Pfeffer, and R. I. Sutton. 2005. "Economic Language and Assumptions: How Theories can Become Self-Fulfilling." Academy of Management Review, 30(1): 8-24.

Fischer, R., R. Callander, P. Reddish, and J. Bulbulia. 2013. "How Do Rituals Affect Cooperation?" Human Nature, 24(2): 115-125. 
Giæver, F. 2019. "Using Choral Singing to Improve Employee Well-Being and Social Cohesion in the Norwegian Public Sector." In E. Antonacopoulou and S. Taylor (eds) Sensuous Learning for Practical Judgment in Professional Practice (pp. 97-115). Palgrave Macmillan.

Giaver, F., J. R. Vaag, and G. Wennes. 2017. "Choral Singing as an Arts-Based Organisational Intervention: A Qualitative Study of Employees' Experiences.” Arts and Health, 9(1): 2641.

Gick, M. L. 2011. "Singing, Health and Well-Being: A Health Psychologist's Review." Psychomusicology: Music, Mind and Brain, 21(1-2): 176-207.

Gillespie, A. S. 2016. Chant and Transformation: The Benedictine Monks of Christ in the Desert Monastery. Thesis, Master of Music, University of New Mexico.

Good, A., and F. A. Russo. 2016. "Singing Promotes Cooperation in a Diverse Group of Children." Social Psychology, 47(5): 340-344.

Graham, C. 1996. Singing, Chanting, Telling Tales: Arts in the Language Classroom. Orlando, FL: Harcourt Brace and Company.

Graafland, J. J. 2018. "Ecological Impacts of the ISO14001 Certification of Small and Medium Sized Enterprises in Europe and the Mediating Role of Networks." Journal of Cleaner Production, 174: 273-282.

Guthrie, S.R. 2003. "Singing, in the Body and in the Spirit." Journal of the Evangelical Theological Society, 46(4): 633-646.

Hacker, R., and W. Tsutsui. 2006. Company Song Comeback. https://kuscholarworks.ku.edu/handle/1808/13722

Hayward, G. D. 2014. Singing as One: Community in Synchrony. Doctoral dissertation, University of Cambridge: Cambridge, UK.

Howard, L. W. 1998. "Validating the Competing Values Model as a Representation of Organizational Cultures." The International Journal of Organizational Analysis, 6(3): 231250.

Jackson, K. 2017. "Music and Virtuosity: A Higher Vision for Business.” Humanistic Management Journal, 2(1): 15-36.

Jansson, D. 2018. The Transfer Space Between Art and Business. Conference paper: The Art of Management and Organization, Brighton, UK, August.

Jeffery, P. 1995. Re-Envisioning Past Musical Cultures: Ethnomusicology in the Study of Gregorian Chant. Chicago: University of Chicago Press.

Kagan, S., and V. Kirchberg. 2016. "Music and Sustainability: Organizational Cultures Towards Creative Resilience-A Review." Journal of Cleaner Production, 135: 1487-1502.

Kapral, J. 2018 (Dec 10). “13 Best (and Worst) Corporate Anthems You'll Wish You Never Heard.”Sidekick, https://blog.kickresume.com/2018/12/10/worst-corporate-anthems/

Kennedy, M. C., 2009. “The Gettin' Higher Choir: Exploring Culture, Teaching and Learning in a Community Chorus." International Journal of Community Music, 2(2-3): 183-200. 
Kingsley, P. 2011 (Aug 19). "The Best Ever Corporate Anthems.” Guardian.

https://www.theguardian.com/music/2011/aug/19/best-ever-corporate-anthems-rahman

Kluver, J., R. Frazier, and J. Haidt. 2014. "Behavioral Ethics for Homo Economicus, Homo Heuristicus, and Homo Duplex." Organizational Behavior and Human Decision Processes 123(2): 150-158.

Kniffin, K. M., J. Yan, B. Wansink, and W. D. Schulze. 2017. "The Sound of Cooperation: Musical Influences on Cooperative Behavior.” Journal of Organizational Behavior, 38(3): 372-390.

Landay, K., and P. D. Harms. 2019. "Whistle While You Work? A Review of the Effects of Music in the Workplace." Human Resource Management Review, 29(3): 371-385.

Langley, M., and L. Coutts. 2020 (March 30). "Why Do We Turn to Music in Times of Crisis?" World Economic Forum, https://www.weforum.org/agenda/2020/03/coronavirus-musiccovid-19-community/

Li, L. 2019 (Sept 24). "“Glory to Hong Kong.' The Composer of City’s Protest Anthem Speaks.” South China Morning Post. https://www.scmp.com/video/scmp-originals/3030172/gloryhong-kong-composer-citys-protest-anthem-speaks

Lidtke, V. L. 1982. "Songs and Nazis: Political Music and Social Change in Twentieth-Century Germany." In Stark, G.D., and B.D. Lackner (eds.) Essays on Culture and Society in Modern Germany (pp. 167-200). College Station: Texas AandM.

Liu, C. H., and P. J. Robertson. 2011. "Spirituality in the Workplace: Theory and Measurement." Journal of Management Inquiry, 20(1): 35-50.

Livesey, L., I. Morrison, S. Clift, and P. Camic. 2012. "Benefits of Choral Singing for Social and Mental Well-Being: Qualitative Findings from a Cross-National Survey of Choir Members.” Journal of Public Mental Health, 11(1): 10-26.

Luhrs, R. R. 2015. Singing for Social Harmony: Choir Member Perceptions During Intergroup Contact. Doctoral dissertation, The Florida State University.

Lynch, T. P. 2009. “'Better than a Hundred Speeches': The Strike Song.” In Brenner, A., B. Daly, and I, Ness (Eds). The Encyclopedia of Strikes in American History (pp. 110-117). Armonk, NY: ME Sharpe.

Martineau, J. 2008. The Elements of Music: Melody, Rhythm, and Harmony. Bloomsbury Publishing USA.

Maxwell, J. R. 2008. "Work System Design to Improve the Economic Performance of the Firm." Business Process Management Journal, 14(3): 432-446.

Mellor, L., 2013. "An Investigation of Singing, Health and Well-Being as a Group Process." British Journal of Music Education, 30(2): 177-205.

Meyer, M. 2019. "The Power of Music: Can Music at Work Help to Create More Ethical Organizations?" Humanistic Management Journal, 4(1): 95-99.

Miles, R. E. and C. C. Snow. 1978. Organization Strategy, Structure and Process. New York: McGraw-Hill.

Morris, A. 2010. "Music in Worship: The Dark Side.” Practical Theology, 3(2): 203-217. 
Morton, C. 2001. "Singing in Unison, Singing in Harmony: Civic Mentorship and Choral Communities." In B. Roberts and A. Rose (eds.), Proceedings of the International Symposium Sharing the Voices: The Phenomenon of Singing 2 (pp. 155-163). St. John's, Newfoundland, CA.

Moss, H. 2019. “Music Therapy, Spirituality and Transcendence.” Nordic Journal of Music Therapy, 28(3): 212-223.

Moss, H., and J. O'Donoghue. 2018. "Sing While You Work-The Well-Being Benefits of Workplace Choirs." Irish World Academy of Music and Dance, University of Limerick.

Müller, V., and U. Lindenberger. 2011. "Cardiac and Respiratory Patterns Synchronize Between Persons During Choir Singing.” PloS one, 6(9), e24893.

Norris, J. K. 2018. Rhythm Entrainment: An Integrative Theory of Interconnectedness. Doctoral Dissertation, California Institute of Integral Studies. San Francisco: USA.

Nissley, N., S. S. Taylor, and O. Butler. 2003. "The Power of Organizational Song: An Organizational Discourse and Aesthetic Expression of Organizational Culture." In Art and Aesthetics at Work (pp. 93-114). London: Palgrave Macmillan.

Poggi, G. 1965. "A Main Theme of Contemporary Sociological Analysis: Its Achievements and Limitations." British Journal of Sociology, 16(4): 283-294.

Prichard, C., M. Korczynski, and M. Elmes. 2007. "Music at Work: An Introduction.” Group and Organization Management, 32(1): 4-21.

Quinn, R. E. 1988. Beyond Rational Management: Mastering the Paradoxes and Competing Demands of High Performance. San Francisco: Jossey-Bass.

Quinn, R. E., and J. Rohrbaugh. 1983. "A Spatial Model of Effectiveness Criteria: Toward a Competing Values Approach to Organizational Analysis.” Management Science, 29(3): 363-377.

Sanger, K. L. 1997. "Functions of Freedom Singing in the Civil Rights Movement: The Activists' Implicit Rhetorical Theory." Howard Journal of Communications, 8(2): 179195.

Schein, E. H. 1985. Organizational Culture and Leadership: A Dynamic View. San Francisco: Jossey Bass.

Schoonderwoerd, P. 2011. "'Shall We Sing a Song for You?': Mediation, Migration and Identity in Football Chants and Fandom." Soccer and Society, 12(1): 120-141.

Scruton, R. 1997. The Aesthetics of Music. Oxford: Clarendon.

Scruton, R. 2011. "Rhythm, Melody, and Harmony." In T. Gracy and A. Kania (Eds), The Routledge Companion to Philosophy and Music (pp. 47-60). Abingdon: Routledge.

Stepanova, E. R., J. Desnoyers-Stewart, P. Pasquier, and B. E. Riecke. 2020. "JeL: Breathing Together to Connect with Others and Nature.” In Proceedings of the 2020 ACM Designing Interactive Systems Conference (pp. 641-654).

Suzuki, N. 1985. "Workers' Perceptions of a Japanese Company's Song." Asia Pacific Journal of Management, 2(3): 189-198. 
Turino, T. 2008. Music as Social life: The Politics of Participation. University of Chicago Press.

Van As, A. J. 2010. Choir Participation as Tool for Transformation and Teambuilding in a Corporate Environment: A Case Study within Absa Bank. Doctoral dissertation, University of Pretoria.

Valdesolo, P., J. Ouyang, and D. DeSteno. 2010. "The Rhythm of Joint Action: Synchrony Promotes Cooperative Ability." Journal of Experimental Social Psychology, 46(4): 693695.

Wald-Fuhrmann, M., S. Boenneke, T. Vroegh, and K. P. Dannecker. 2020. “'He Who Sings, Prays Twice'? Singing in Roman Catholic Mass Leads to Spiritual and Social Experiences That Are Predicted by Religious and Musical Attitudes." Frontiers in Psychology, 11: 113.

Wiltermuth, S. S., and C. Heath. 2009. "Synchrony and Cooperation." Psychological Science, 20(1): $1-5$.

Winter, K. F. 2009. A Phenomenological Experience of Singing Vocal Harmony with Another Person. Master's Thesis, Creative Arts in Therapy, Drexel University.

Werber, C. 2019 (May 20). “The Surprising Benefits of Singing at Work." Quartz at Work. https://qz.com/work/1613520/brits-are-fighting-burnout-by-joining-workplace-choirs/

Wlodarczyk, N. 2007. "The Effect of Music Therapy on the Spirituality of Persons in an InPatient Hospice Unit as Measured by Self-Report." Journal of Music Therapy, 44(2): 113122. 
FIGURE 1

\section{Overview of hypothesized relationships between}

\section{types of organizational culture and types of corporate singing}

\begin{tabular}{l|c|}
$\begin{array}{l}\text { Emphasis on change and } \\
\text { adaptability }\end{array}$ & $\begin{array}{c}\text { Clan culture } \\
\text { Harmony singing } \\
\text { Mixed singing }\end{array}$ \\
$\begin{array}{l}\text { Emphasis on stability and } \\
\text { predictability }\end{array}$ & $\begin{array}{c}\text { Market culture } \\
\text { Unison singing }\end{array}$ \\
(e.g., nurture existing members) & $\begin{array}{c}\text { External emphasis } \\
\text { Chanting }\end{array}$ \\
(e.g., reach out to others)
\end{tabular}

